\title{
HERNIECTOMY WITHOUT DISCECTOMY IN EXTRUDED LUMBAR DISC HERNIATION; SHOULD IT BE THE GOLD STANDARD?
}

\author{
(1) Md Moshiur RAHMAN
}

Holy Family Red Crescent Medical College, Department of Neurosurgery, Dhaka, Bangladesh

\begin{abstract}
Objective: Microdiscectomy in lumbar disc herniation (LDH) is the gold standard treatment, but conventional discectomy is still the most widely used across the world. This study aimed to evaluate the treatment outcomes of herniectomy compared to conventional discectomy for an extruded lumbar disc.

Materials and Methods: A total of 788 patients were included in the study. Of this population, 548 were males and 240 were females. This was a retrospective study that was conducted from 2009 to 2018. Conventional discectomy and herniectomy for the treatment of extruded LDH were compared. Minimum follow-up period was 2 years.

Results: Most of the patients were pain-free in both procedures (herniectomy and conventional discectomy). The surgical outcome of herniectomy did not significantly differ by age, gender, educational background, preoperative VAS for back, preoperative VAS for radicular pain, Oswestry disability index score, return to the previous job and level of herniation in comparison to conventional microdiscectomy.

Conclusion: Herniectomy in extruded lumbar disc prolapse is similar compared to conventional discectomy in terms of pain removal and recurrent disc prolapse. Furthermore, removal of only the herniated disc preserves the disc height, which has many advantages including functional mobility and no alteration in the diameter of the intervertebral foramen. Also, a decrease in the incidence of adjacent level disc prolapse may be due to low stress in relation to conventional discectomy. It is still not clear whether the herniectomy in extruded lumbar disc surgery should be a gold standard or not.

Keywords: Herniectomy, disc herniarion, extruded lumbar, discectomy
\end{abstract}

\section{INTRODUCTION}

Lumbar disc herniation (LDH), which primarily consists of back pain and radiculopathy, is a common condition occurring in most elderly peoples in a lifetime. In the general population, the incidence of $L D H$ is reported as $1 \%$ to $2 \%$ and 4.86 per 1000 young population ${ }^{(1-3)}$. LDH can cause severe symptoms, such as intermittent low back pain, sciatica in patients, etc. In such cases, the treatment goal is to reduce pain and inflammation ${ }^{(4)}$. The implementation of microsurgical techniques has marked a significant development in the treatment of lumbar discs herniation. Microsurgery is considered today as a gold standard procedure.LDH surgery can be done using a camera,known as an endoscope, as well as micro-incisions of the skin. Furthermore, advanced technological devices such as special surgical microscopes and microsurgical instruments, which in current neurosurgical practice are considered the gold standard, can be used to imagine the three-dimensional and distorted images of herniated discs and tissues ${ }^{(5)}$. Postoperative complications such as neural tissue damage can be decreased with the surgical procedure, and disc material can be removed safely. There is evidence that although re-herniations occur in approximately $10 \%$ of patients, clinical deterioration is mostly attributable to chronic lower back pain in up to $75 \%$ of patients after 10 years ${ }^{(6,7)}$. A less invasive method was demonstrated earlier, the so-called limited discectomy, which involved removing only extruded fragments and any loose pieces in the disc space using only pituitary forceps to remove the free fragments. Subsequently, there was a growing interest in conservative surgery leading to minimal clearance of intradiscal tissue, which is microscopic herniectomy/sequestrectomy/free fragmentectomy. In this subpopulation of disc herniations, it requires only the simple excision of the disc fragment. The herniated fragment was established as the offending agent; however, it has always been considered necessary to extract either a fragment or the entire disc. The incidence of herniectomy in the treatment of LDH is gradually increasing. The term "herniectomy" is defined as the elimination of the herniated disc fragment only, while the 
conventional discectomy is the elimination of the herniated disc and degenerative nucleus from the intervertebral disc space. In this study, we conducted a comparative analysis between conventional discectomy and herniectomy in extruded LDH. Our main goal of the study is to determine whether herniectomy should be the first choice of surgery in an extruded lumbar disc in comparison to conventional discectomy.

\section{MATERIALS AND METHODS}

This is a retrospective study conducted from 2009 to 2018 in three private hospitals, Dhaka, Bangladesh. IRB/Ethical Committee approval was not taken. For this study, informed written patient consent as well as written consent for publication was taken from 788 patients.

\section{Patient Data, Study Design and Study Criteria}

This comparative study between conventional discectomy and herniectomy was performed in patients with extruded LDH. Patients who suffer from extruded LDH, of both genders and who meet the inclusion criteria were included in the study. From 2009 to 2018, among 1.200 patient's retrospective data chart, a total of 788 patients met the inclusion criteria and they were randomly and equally assigned to both groups (conventional discectomy and herniectomy). Of this population, 548 were males and 240 were females. A single surgeon (author) operated in all the patients. All the patients consented to the surgical procedures, and written informed consent was obtained from all patients for publication of their cases and accompanying images.

Patients having back pain with sciatica who were not improved by conservative treatment for 8 weeks were included in the study. Patients having more than one level herniation, spinal canal stenosis, instability and incomplete follow up were excluded from the study. From the patients' hospital records, age, gender, occupation, recurrence time (days), the level herniations and the type of surgery were examined by the same surgeon. Patient data were obtained from chart reviews and patientbased outcome questionnaires or follow-ups. Each patient was followed-up at 6 weeks, 6 months, 1 year and 2 years. At each follow-up, the patients completed questionnaires that reflected their functional state and pain severity. The patient's pain levels were assessed using the visual analogue scale (VAS) score. The functional state was assessed using the Oswestry disability index (ODI). Magnetic resonance imaging of the lumbosacral spine was evaluated at 6 weeks postoperatively where patients were nonresponsive to conservative treatment for persistent symptoms like back or leg pain, weakness and also considered for patients having recurrent symptoms at any time (Figures 1 , $2,3)$. The long-term surgical outcomes were evaluated.

In our study, we observed that among 788 patients, a total of $70 \%$ (551 patients) were heavy workers. There, we found that $58 \%$ (457 patients) were male-heavy workers and 12\% (94 patients) were female-heavy workers (Table 1 ).

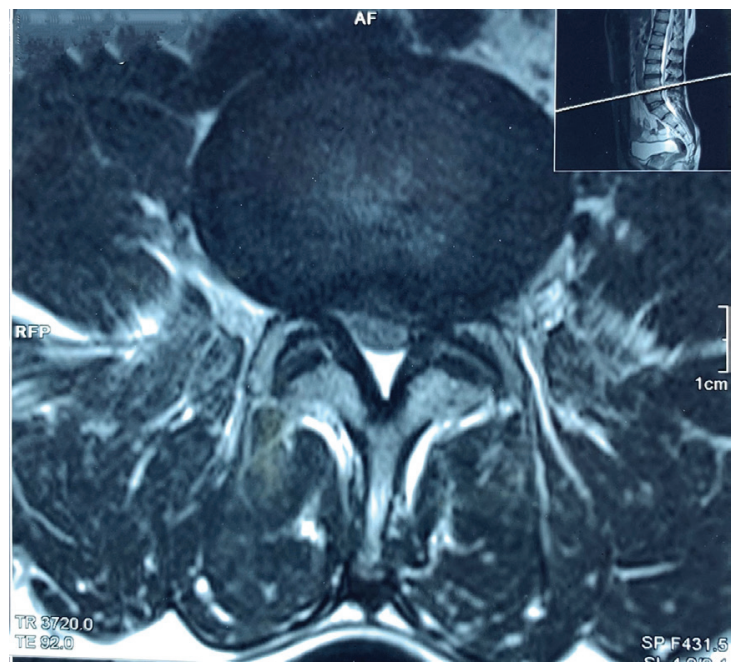

Figure 1. Axial T2-weighted MRI image of the Lumbar spine showing herniated disc on left $L 4 / 5$ space MRI: Magnetic resonance imaging

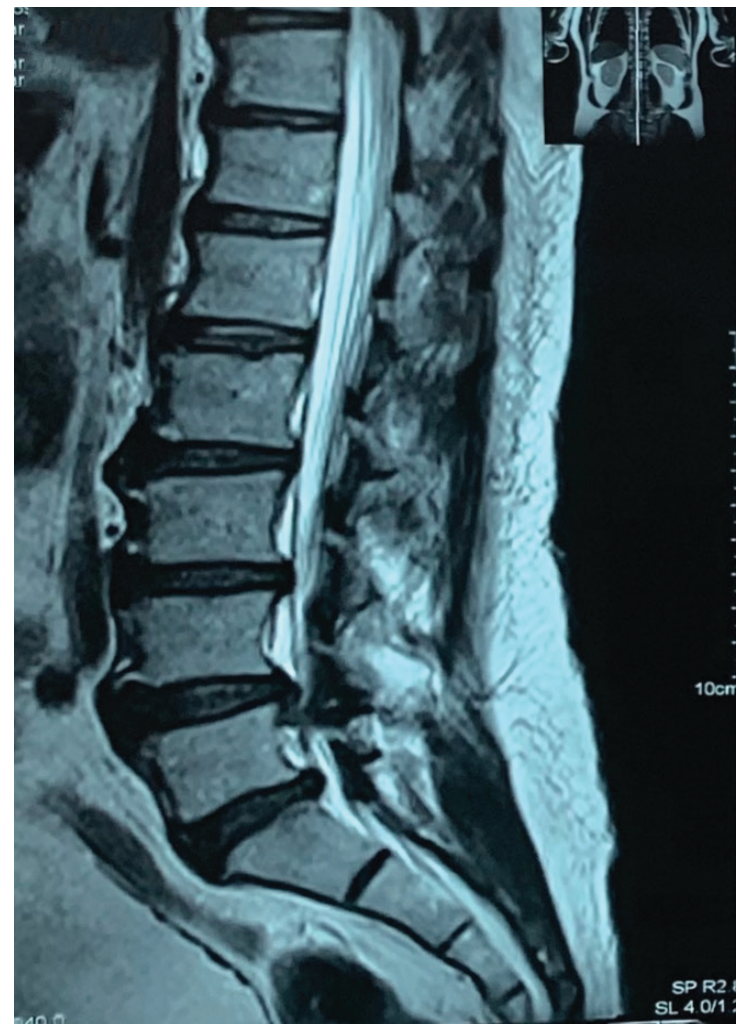

Figure 2. Sagittal T2-weighted MRI image of the lumbar spine showing downward herniated disc at $L 4 / 5$ on the right side MRI: Magnetic resonance imaging

Table 1. Job types of selected patients

\begin{tabular}{lll}
\hline Gender & Heavy workers & Educated $^{*}$ \\
\hline Male & $457(58 \%)$ & $91(11 \%)$ \\
\hline Female & $94(12 \%)$ & $146(19 \%)$ \\
\hline Total & $70 \%$ & $30 \%$ \\
\hline
\end{tabular}

*Educated-selected patients who can write their names 


\section{Statistical Analysis}

The comparison between pre and postoperative clinical outcomes in pain and functional state was performed using repeated-measures analysis. Using descriptive statistical methods, the mean and standard deviation was assessed by the SPSS version 25 statistical package. All analyses were performed here using the SPSS tool. P values $<0.05$ were considered significant.

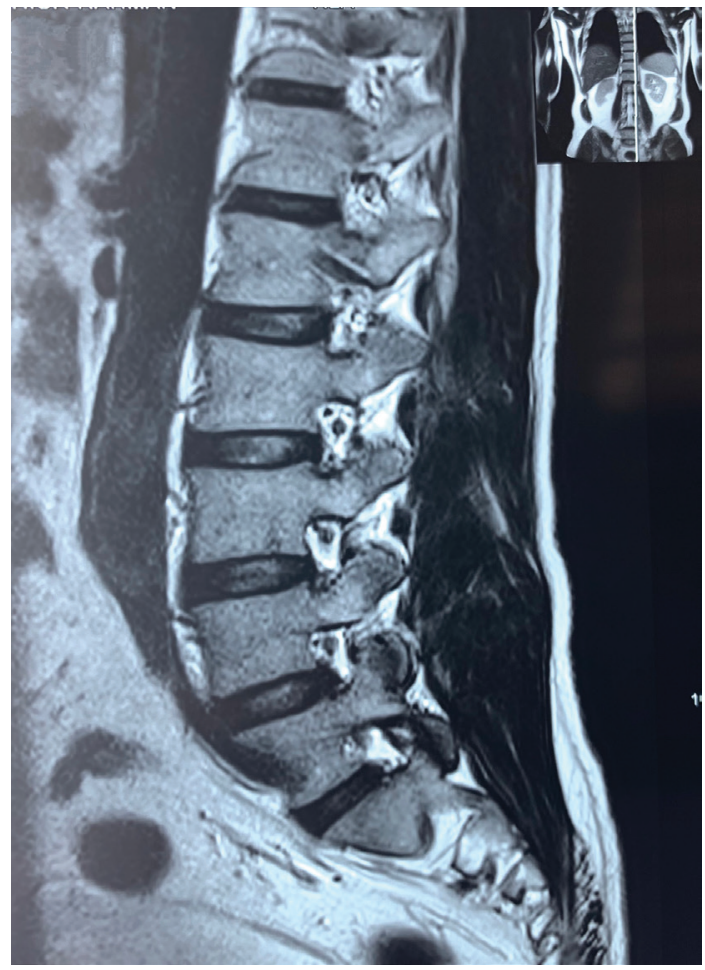

Figure 3. Sagittal T2-weighted MRI image of the Lumbar spine showing left intervertebral foramen in a post herniectomy patient MRI: Magnetic resonance image

\section{RESULTS}

The outcome of herniectomy did not significantly differ by age, gender, level of re-herniation in comparison to conventional microdiscectomy. In our study, among the 788 patients, 394 patients underwent herniectomy and 394 patients conventional discectomy. The mean ages were $47.32 \pm 53.90$ years in the herniectomy group and $52.67 \pm 21.38$ years in the conventional discectomy group. Recurrence was observed in 24 (6\%) patients in the herniectomy group and $32(8 \%)$ patients in the discectomy group. Although the discectomy group had a higher recurrence rate, this was not a significantly different $(p=0.530)$. Recurrence levels ranged in the order of common cases and the average recurrent intervals were 20 weeks in herniectomy and 22 weeks in conventional discectomy group (Table 2). In comparison to the conventional discectomy group, the herniectomy group had low recurrences, probably due to decreased mechanical load to the lumbar spine (male-heavy workers were more in the conventional discectomy group).

The VAS score was obtained before and two weeks after surgery. Some patients score was unobtainable in both the herniectomy and conventional discectomy groups (Table 3 ).

Among all the patients in our study, the level of disc herniations are shown in Table 4. Also, the preoperative and postoperative diameter of intervertebral disc foramen in both groups are shown in Table 5. The amount of reduced disc height and foramen diameter in both group of patients are shown in Table 5.

The mean preoperative ODI score was $63.28 \%$ in herniectomy group and $62.56 \%$ in the conventional discectomy group. In the herniectomy group, the mean postoperative ODI score was reduced to $35.81 \%, 24.73 \%, 17.37 \%$ and $16.02 \%$ at postoperative 6 weeks, 6 months, 1 year and 2 years, respectively $(p<0.001)$. And in the conventional discectomy group, the mean

Table 2. Characteristics of patients according to herniectomy and conventional discectomy

\begin{tabular}{|c|c|c|c|}
\hline Characteristics & $\begin{array}{l}\text { Herniectomy } \\
(n=394)\end{array}$ & $\begin{array}{l}\text { Conventional discectomy } \\
(n=394)\end{array}$ & $p$ value \\
\hline Gender (male, female) & 272,122 & 276,118 & 0.069 \\
\hline Recurrence & $24(6 \%)$ & $32(8 \%)$ & 0.530 \\
\hline Mean length of time of recurrence & 20 weeks & 22 weeks & 0.089 \\
\hline
\end{tabular}

Table 3. Visual analogue scale comparison

\begin{tabular}{llll}
\hline Groups & Preoperative VAS & Postoperative VAS & p value \\
\hline Microdiscectomy $(\mathrm{n}=394)$ & 6.9 & 1.8 & 0.081 \\
\hline Herniectomy $(\mathrm{n}=394)$ & 7.2 & 1.3 & 0.063 \\
\hline VAS: Visual analogue scale, $\mathrm{n}$ : Number & & & \\
\hline
\end{tabular}


postoperative ODI score was reduced to $38.25 \%, 28.62 \%, 19.82 \%$ and $18.59 \%$ at postoperative 6 weeks, 6 months, 1 year and 2 years, respectively $(p<0.001)$ (Figure 4$)$. The total reduction of ODI score after 2 years was $47.26 \%$ in herniectomy group and $43.97 \%$ in the conventional discectomy group.

Most of the patients were pain-free after surgery. We found that in the herniectomy group, more (39.35\%) patients had a good outcome and $33.02 \%$ patients had an excellent outcome. In the conventional discectomy group, $38.10 \%$ patients had a good outcome and $28.43 \%$ patients had an excellent outcome. Also, only a few patients' surgical outcome was poor in both groups
(Figure 5). The surgical outcome was comparatively better in the herniectomy than the discectomy group.

Other than recurrences of disc prolapse, there were some complications observed in patients of both groups. The worsening of neurological deficit, incidental durotomy, hematoma, discitis and deep vein thrombosis were the side effects in patients (Table 6).

The study showed that patients treated with herniectomy had an equal length of hospital stay compared with those treated with microdiscectomy. The mean time of returning to normal life was 17.19 and 22.04 days in the herniectomy and microdiscectomy

Table 4. Level of the disc herniations

\begin{tabular}{lll}
\hline Level of disc herniation & $\begin{array}{l}\text { Herniectomy } \\
(\mathbf{n}=394)\end{array}$ & $\begin{array}{l}\text { Conventional discectomy } \\
(\mathbf{n}=394)\end{array}$ \\
\hline L1/L2 & 2 & 2 \\
\hline L2/L3 & 5 & 6 \\
\hline L3/L4 & 14 & 11 \\
\hline L4/L5 & 190 & 195 \\
\hline L5/S1 & 183 & 180 \\
\hline n: Number & & \\
\hline
\end{tabular}

Table 5. Diameter of the intervertebral disc foramen in magnetic resonance imaging

\begin{tabular}{|c|c|c|c|c|}
\hline \multirow{3}{*}{$\begin{array}{l}\text { Level of } \\
\text { disc herniation }\end{array}$} & \multicolumn{4}{|c|}{ Intervertebral foramen diameter (mm) } \\
\hline & \multicolumn{2}{|c|}{ Herniectomy } & \multicolumn{2}{|c|}{ Conventional discectomy } \\
\hline & Preop & Postop & Preop & Postop \\
\hline L1/L2 & $17.27 \mathrm{~mm}$ & $17.27 \mathrm{~mm}$ & $17.22 \mathrm{~mm}$ & $16.43 \mathrm{~mm}$ \\
\hline L2/L3 & $18.19 \mathrm{~mm}$ & $18.19 \mathrm{~mm}$ & $18.18 \mathrm{~mm}$ & $17.33 \mathrm{~mm}$ \\
\hline L3/L4 & $17.45 \mathrm{~mm}$ & $17.45 \mathrm{~mm}$ & $17.41 \mathrm{~mm}$ & $16.30 \mathrm{~mm}$ \\
\hline L4/L5 & $16.71 \mathrm{~mm}$ & $16.71 \mathrm{~mm}$ & $16.79 \mathrm{~mm}$ & $15.58 \mathrm{~mm}$ \\
\hline L5/S1 & $15.23 \mathrm{~mm}$ & $15.23 \mathrm{~mm}$ & $15.45 \mathrm{~mm}$ & $13.94 \mathrm{~mm}$ \\
\hline
\end{tabular}

Preop: Preoperative, Postop: Postoperative

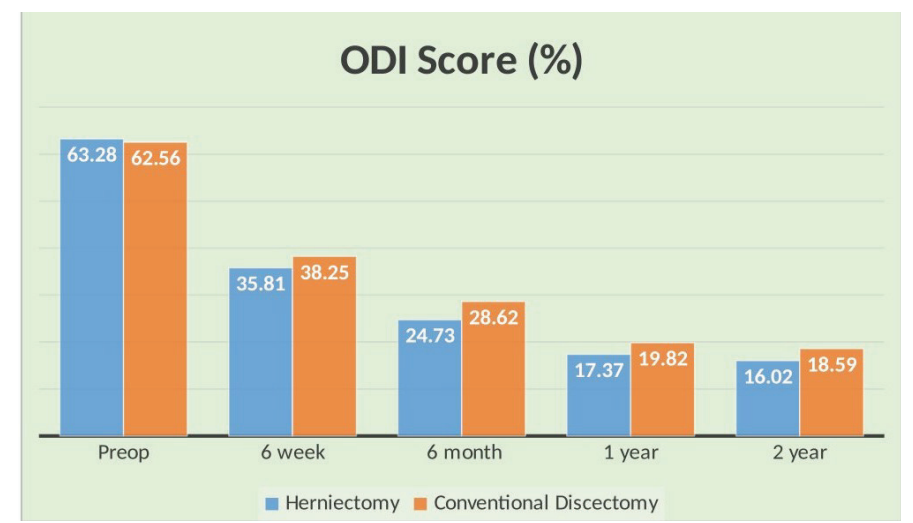

Figure 4. Oswestry disability index scores obtained in the preop and postop periods in both groups

ODI: Oswestry disability index, Preop: Preoperative, Postop: Postoperative

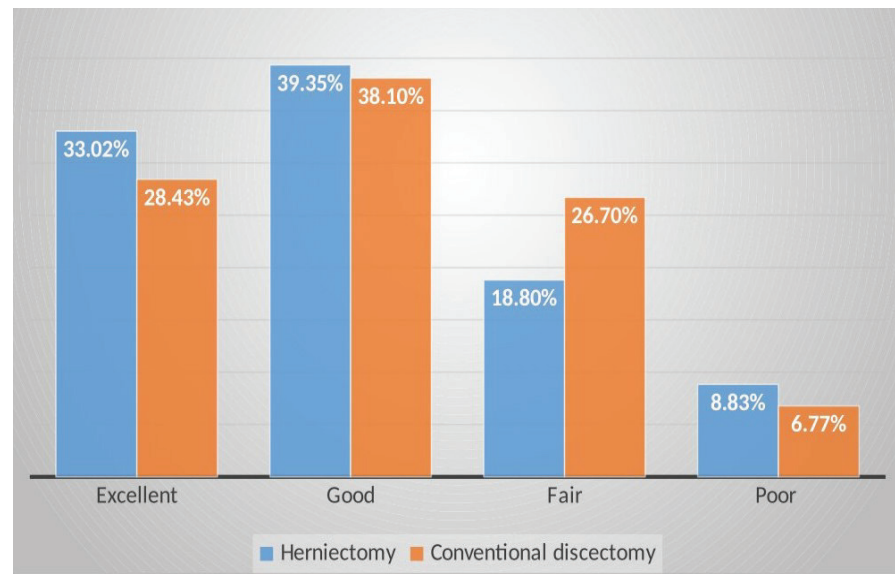

Figure 5. Level of outcome after surgery in both groups 
turkishspine

groups, respectively. The patients of both groups showed an almost similar response, but patients with herniectomy recovered earlier than those in the microdiscectomy group (Table 7).

\section{DISCUSSION}

Our study found that in comparison to conventional discectomy, the herniectomy group had better and more effective outcomes. Here, the herniectomy group had lower recurrent cases and lower complication rates as compared to conventional microdiscectomy in LDH. The disc heights were preserved by removing the herniated discs. It was very beneficial as there was no change in functional mobility and intervertebral foramen diameter in herniectomy.

In 1978, Williams ${ }^{(8)}$ recommended a conservative surgical approach to the virgin herniated lumbar disc by making only blunt perforation in the fibrous wiring. Conventionally, microdiscectomy-related neural decompression was accomplished by excising the herniated disc material, resection of any possible intervertebral tissue and endplate curettage(9). This conventional microdiscectomy technique was based on the assumption that by increasing the amount of resected disc tissue, the probability of re-herniation would be reduced ${ }^{(10)}$. Complete removal of all disc material is impossible $e^{(11,12)}$. Repeated surgeries could therefore not be stopped when these methods were used ${ }^{(13,14)}$.

Herniectomy results were pleasingly compared with those achieved after a microdiscectomy in this study. Although no statistical differences were observed, the rate of recurrence was $6 \%$ in the herniectomy group and $8 \%$ in the microdiscectomy group. In our study, most (70\%) patients were heavy workers. This type of occupation is one important reason for these cases. Recurrences were lower in herniectomy probably because of less mechanical load to the lumbar spine, as there were more heavy workers in the conventional discectomy group. Upon excision of only the herniated fragments, a study reported a recurrence rate of $21 \%$ (7 of 33 patients) ${ }^{(15)}$. A study reported that within the first 9 months, $92 \%$ of re-herniations occurred, and another study indicated that most recurrences occurred within the first 6 months $^{(15,16)}$. Despite the need for a longer follow-up study, we believe our findings provide some proof that re-herniations after herniectomy are not significantly increased.

The postoperative VAS of the conventional discectomy group declined in a similar manner to that in the herniectomy group. This may be because the postoperative VAS was checked one week after the surgery. However, we expect that the long-term VAS and clinical outcomes in the herniectomy group will show a better result.

Two years after surgery, postoperative mean ODI was decreased to $16.02 \%$ in the herniectomy group and $18.59 \%$ in the conventional discectomy group. In comparison to the preoperative scores, more reduction was observed in herniectomy group. A reduction in the ODI score of more than $20 \%$ was considered clinically relevant ${ }^{(17,18)}$.

A systematic review study suggests that herniectomy may result in shorter operating time and faster return to work ${ }^{(19)}$. Our studied patients of the herniectomy group also returned to normal life faster than the discectomy group. The additional advantage of herniectomy is that abdominal or retroperitoneal damage is prevented due to non-entry into the disc space.

\section{Study Limitations}

This retrospective study has limitations. First, better procedures are required for exploring outcome prediction and identifying accurate predictors of surgical outcome in long-term follow-up after LDH surgery. In addition, further studies are needed to improve the prediction accuracy and identify reliable predictors of surgical outcomes in patients with a variety of LDH.

Table 6. Complications

\begin{tabular}{lll}
\hline Factors & $\begin{array}{l}\text { Herniectomy } \\
\mathrm{n}(\%)\end{array}$ & $\begin{array}{l}\text { Conventional discectomy } \\
\mathrm{n}(\%)\end{array}$ \\
\hline Worsening of neurological deficit & $7(1.8 \%)$ & $8(2 \%)$ \\
\hline Incidental durotomy & $15(3.8 \%)$ & $16(4 \%)$ \\
\hline Hematoma & $3(0.7 \%)$ & $3(0.7 \%)$ \\
\hline Recurrent disc prolapse & $24(6 \%)$ & $32(8 \%)$ \\
\hline Discitis & $2(0.5 \%)$ & $2(0.5 \%)$ \\
\hline Deep vein thrombosis & $1(0.25 \%)$ & $1(0.25 \%)$ \\
\hline
\end{tabular}

Table 7. Comparison of mean operating time, hospital stay and returning to daily life between both groups

\begin{tabular}{llll}
\hline Groups & $\begin{array}{l}\text { Operating time } \\
\text { (Minutes; mean) }\end{array}$ & $\begin{array}{l}\text { Hospital-stay } \\
\text { (Day; mean) }\end{array}$ & $\begin{array}{l}\text { Returning to daily life } \\
\text { (Day; mean) }\end{array}$ \\
\hline Herniectomy $(n=394)$ & 38.19 & 2.4 & 17.19 \\
\hline Microdiscectomy $(n=394)$ & 42.76 & 2.4 & 22.04 \\
\hline n: Number & & & \\
\hline
\end{tabular}




\section{CONCLUSION}

The herniectomy is successful with shorter operating time, lower perioperative complication rates and lower re-herniation rate as compared to conventional microdiscectomy in LDH. Compared with conventional discectomy, performing herniectomy in the extruded lumbar disc prolapse is similar to pain removal and recurrent disc prolapse. However, the removal of only the herniated disc preserves the height of the disc, which has many advantages including functional mobility and no alteration of intervertebral foramen diameter, as well as a decrease in the incidence of adjacent disc prolapse due to low stress in comparison to conventional discectomy, which may need a much longer follow-up for exact evaluation. Herniectomy did not seem to entail a higher rate of recurrences compared with a conventional discectomy in this series. It is still not certain whether herniectomy in extruded lumbar disc surgery should be a gold standard treatment or not.

\section{Acknowledgments}

The author would like to thank all the members who were part of this research for their cooperation and help in preparing all the information.

\section{Ethics}

Ethics Committee Approval: This is a retrospective study conducted from 2009 to 2018 in three private hospitals, Dhaka, Bangladesh. IRB/Ethical Committee approval was not taken.

Informed Consent: For this study, informed written patient consent as well as written consent for publication was taken from 788 patients.

Peer-review: Externally peer-reviewed.

Financial Disclosure: No specific funding was provided for this research paper.

\section{REFERENCES}

1. Deyo RA, Tsui-Wu YJ. Descriptive epidemiology of low-back pain and its related medical care in the United States. Spine (Phila Pa 1976). 1987; 12:264-8.

2. Rhee JM, Schaufele M, Abdu WA. Radiculopathy and the Herniated Lumbar Disc. Controversies Regarding Pathophysiology and Management. J Bone Joint Surg Am. 2006;88:2070-80.

3. Schoenfeld AJ, Laughlin M, Bader JO, Bono CM. Characterization of the incidence and risk factors for the development of lumbar radiculopathy. J Spinal Disord Tech. 2012;25:163-7.
4. Lee J, Shin JS, Lee YJ, Kim MR, Ahn YJ, Park KB, et al. Effects of Shinbaro pharmacopuncture in sciatic pain patients with lumbar disc herniation: study protocol for a randomized controlled trial. Trials. 2015;16:455.

5. Teng Huang, Zhi Tian, Mengya Li, Zheng W, Zhang L, Chen J, et al. Sequestrectomy versus microdiscectomy in the treatment of lumbar disc herniation: a meta-analysis. Int J Clin Exp Med. 2015;8:72619.

6. Davis SJ. A long-term outcome analysis of 984 surgically treated herniated lumbar discs. J Neurosurg. 1994;80:415-21.

7. Yoriuitsu L, Chiba K, Toyama Y, Hirabayashi K. Long term outcomes of standard discectomy for lumbar disc herniation: a follow-up study of more than 10 years. Spine. 2001;26;652-7.

8. Williams RW. Microlumbar discectomy, a conservative surgical approach to the virgin herniated lumbar disc. Spine. 1978;3:75-82.

9. Caspar W. A new surgical procedure for lumbar disc herniation causing less tissue damage through a microsurgical approach. Lumbar Disc Adult Hydrocephalus: Springer-Verlag Berlin Heidelberg 1977,pp:74-80.

10. Wenger M, Mariani L, Kalbarczyk A, Gröger U. Long-term outcome of 104 patients after lumbar sequestrectomy according to Williams. Neurosurgery. 2001;49:329-34.

11. Hudgins R. Experience with limited versus extensive disc removal in patients undergoing microsurgical operations for ruptured lumbar discs (comment). Neurosurgery. 1988;22:85.

12. McCulloch JA. Focus issue on lumbar disc herniation: macro- and microdiscectomy. Spine. 1996;21:45S-56S.

13. Caspar W, Campbell B, Barbier DD, Kretschmmer R, Gotfried Y. The Caspar microsurgical discectomy and comparison with a conventional standard lumbar disc procedure. Neurosurgery. 1991;28:78-86.

14. Davis RA. A long-term outcome analysis of 984 surgically treated herniated lumbar discs. Journal of Neurosurgery. 1994;80:415-21.

15. Rogers LA. Experience with limited versus extensive disc removal in patients undergoing microsurgical operations for ruptured lumbar discs. Neurosurgery. 1988;22:82-5.

16. Williams RW. Microlumbar discectomy. A 12-year statistical review. Spine. 1986;11:851-2.

17. $\mathrm{Ng}$ LC, Tafazal S, Sell P. The effect of duration of symptoms on standard outcome measures in the surgical treatment of spinal stenosis. Eur Spine J. 2007;16:199-206.

18. Ostelo RW, Deyo RA, Stratford P, Waddell G, Croft P, Von Korff M, et al. Interpreting change scores for pain and functional status in low back pain: towards international consensus regarding minimal important change. Spine (Phila Pa 1976). 2008;33:90-4.

19. Watters WC, McGirt MJ. An evidence-based review of the literature on the consequences of conservative versus aggressive discectomy for the treatment of primary disc herniation with radiculopathy. Spine J. 2009;9:240-57. 